\title{
Modelling uveal melanoma
}

Alexander J E Foss, Ian A Cree, Paul J Dolin, John L Hungerford

\begin{abstract}
Backgroundlaim-There has been no consistent pattern reported on how mortality for uveal melanoma varies with age. This information can be useful to model the complexity of the disease. The authors have examined ocular cancer trends, as an indirect measure for uveal melanoma mortality, to see how rates vary with age and to compare the results with their other studies on predicting metastatic disease.

Methods-Age specific mortality was examined for England and Wales, the USA, and Canada. A log-log model was fitted to the data. The slopes of the log-log plots were used as measure of disease complexity and compared with the results of previous work on predicting metastatic disease.
\end{abstract}

Results-The log-log model provided a good fit for the US and Canadian data, but the observed rates deviated for England and Wales among people over the age of 65 years. The log-log model for mortality data suggests that the underlying process depends upon four rate limiting steps, while a similar model for the incidence data suggests between three and four rate limiting steps. Further analysis of previous data on predicting metastatic disease on the basis of tumour size and blood vessel density would indicate a single rate limiting step between developing the primary tumour and developing metastatic disease.

Conclusions-There is significant underreporting or underdiagnosis of ocular melanoma for England and Wales in those over the age of 65 years. In those under the age of 65 , a model is presented for ocular melanoma oncogenesis requiring three rate limiting steps to develop the primary tumour and a fourth rate limiting step to develop metastatic disease. The three steps in the generation of the primary tumour involve two key processesnamely, growth and angiogenesis within the primary tumour. The step from development of the primary to development of metastatic disease is likely to involve a single rate limiting process.

(Br F Ophthalmol 1999;83:588-594)

Cancers of the eye are rare tumours, accounting for less than $0.1 \%$ of all cancer deaths in the USA and England and Wales, with a large majority of these due to uveal melanoma. ${ }^{12}$ Despite its rarity, this tumour carries a $50 \% 5$ year mortality. ${ }^{3}$ The two most widely discussed models - the enucleation hypothesis ${ }^{4}$ and the Manschot-Van Peperzeel hypothesis ${ }^{5}$-have caused considerable controversy. There have been no recent attempts to model the disease.

Zimmerman et al noted "the rapid rise in mortality, reaching a peak during the second postenucleation year" ${ }^{4}$ and questioned the safety of enucleation for uveal melanoma. This peak in mortality was followed by a fall and was independent of the size of the primary tumour. The authors argued that the most likely explanation would be some event occurring at the time of presentation and suggested that surgical manipulation was the cause of metastatic spread. $^{78}$

The concept of surgical manipulation causing dissemination is a perennial one dating back at least as far as the work of Joynes and Rous. ' There is no good evidence to support this model, however, in the case of uveal melanoma. The observation of peak hazard at year two was largely artefactual, owing to an error in how Zimmerman et al plotted their hazard functions ${ }^{10}$ and certainly no such effect can be seen on the survivorship curves from our data (see below). In addition, histological markers of traumatic enucleation carry no adverse prognostic significance, ${ }^{11}$ preenucleation radiotherapy carries no benefit, ${ }^{12-15}$ and the most direct evidence is that no shedding of cells at the time of surgery can be found using the highly sensitive technique of RT-PCR. ${ }^{16}$

An alternative hypothesis proposed by Manschot and van Peperzeel was based on the assumption that metastatic deposits grow at a similar rate to the primary tumour. This led to the conclusion that dissemination must occur at around the third doubling time or, in other words, close to the onset of the disease. ${ }^{56}$ Primary melanomas grow at a very slow rate and the observed lag between diagnosis of the primary and diagnosis of metastatic disease is similar to three times the estimates of the tumour doubling time. The corollary of this was that the enucleation hypothesis was clearly incorrect as seeding must have occurred years before any diagnosis and surgical intervention, with the implication that no treatment made any difference to prognosis. The assumption that underlies the Manschot-Van Peperzeel hypothesis-that secondary deposits grow at the same rate as the primary tumour-has been disproved by evidence that metastatic deposits grow more aggressively. ${ }^{17}$ Nor does this hypothesis explain the existence of long term survivors following enucleation, compared with near $100 \%$ mortality among patients refusing treatment. ${ }^{18} 19$
Accepted for publication 25 November 1998 
Table 1 Poisson model for England and Wales

\begin{tabular}{|c|c|c|c|c|c|}
\hline Variable & Coefficient & $\begin{array}{l}\text { Standard } \\
\text { error }\end{array}$ & $p$ Value & $95 \%$ confider & nce interval \\
\hline \multicolumn{6}{|l|}{ Sex } \\
\hline Female & -0.236 & 0.030 & 0.000 & -0.294 to & -0.178 \\
\hline \multicolumn{6}{|l|}{ Age } \\
\hline $45-49$ & 0.570 & 0.108 & 0.000 & 0.359 to & 0.782 \\
\hline $50-54$ & 0.998 & 0.101 & 0.000 & 0.800 to & 1.120 \\
\hline $55-59$ & 1.480 & 0.096 & 0.000 & 1.292 to & 1.668 \\
\hline $60-64$ & 1.838 & 0.94 & 0.000 & 1.656 to & 2.022 \\
\hline $65-69$ & 2.098 & 0.093 & 0.000 & 1.916 to & 2.280 \\
\hline $70-74$ & 2.231 & 0.094 & 0.000 & 2.047 to & 2.414 \\
\hline $75-79$ & 2.249 & 0.097 & 0.000 & 2.060 to & 2.438 \\
\hline $80-84$ & 2.330 & 0.102 & 0.000 & 2.130 to & 2.531 \\
\hline $85+$ & 2.536 & 0.108 & 0.000 & 2.324 to & 2.531 \\
\hline \multicolumn{6}{|l|}{ Time period } \\
\hline $1960-64$ & 0.091 & 0.061 & 0.133 & -0.028 to & 0.210 \\
\hline $1965-69$ & 0.128 & 0.059 & 0.030 & 0.012 to & 0.2444 \\
\hline $1970-74$ & 0.250 & 0.057 & 0.000 & 0.137 to & 0.362 \\
\hline $1975-79$ & 0.164 & 0.057 & 0.005 & 0.051 to & 0.278 \\
\hline $1980-84$ & 0.124 & 0.058 & 0.033 & 0.010 to & 0.238 \\
\hline $1985-89$ & 0.079 & 0.058 & 0.175 & -0.035 to & 0.194 \\
\hline Constant & -13.59 & 0.096 & 0.000 & -13.777 to & -13.400 \\
\hline
\end{tabular}

Table 2 Poisson model for the USA

\begin{tabular}{|c|c|c|c|c|c|}
\hline Variable & Coefficient & $\begin{array}{l}\text { Standard } \\
\text { error }\end{array}$ & $p$ Value & $95 \%$ confider & nce interval \\
\hline \multicolumn{6}{|l|}{ Sex } \\
\hline Female & -0.243 & 0.030 & 0.000 & -0.285 to & -0.201 \\
\hline \multicolumn{6}{|l|}{ Age } \\
\hline $45-49$ & 0.555 & 0.082 & 0.000 & 0.394 to & 0.715 \\
\hline $50-54$ & 1.042 & 0.076 & 0.000 & 0.893 to & 1.192 \\
\hline $55-59$ & 1.494 & 0.073 & 0.000 & 1.351 to & 1.636 \\
\hline $60-64$ & 1.916 & 0.071 & 0.000 & 1.778 to & 2.056 \\
\hline $65-69$ & 2.233 & 0.070 & 0.000 & 2.096 to & 2.370 \\
\hline $70-74$ & 2.478 & 0.070 & 0.000 & 2.341 to & 2.616 \\
\hline $75-79$ & 2.661 & 0.071 & 0.000 & 2.521 to & 2.800 \\
\hline $80-84$ & 2.974 & 0.073 & 0.000 & 2.521 to & 2.800 \\
\hline $85+$ & 3.415 & 0.073 & 0.000 & 3.271 to & 3.558 \\
\hline \multicolumn{6}{|l|}{ Time period } \\
\hline $1960-64$ & -0.072 & 0.037 & 0.052 & -0.144 to & 0.001 \\
\hline $1965-69$ & -0.179 & 0.037 & 0.000 & -0.252 to & -0.107 \\
\hline $1970-74$ & -0.196 & 0.042 & 0.000 & -0.278 to & -0.114 \\
\hline $1975-79$ & -0.389 & 0.043 & 0.000 & -0.473 to & -0.304 \\
\hline $1980-84$ & -0.635 & 0.039 & 0.000 & -0.711 to & -0.560 \\
\hline $1985-89$ & -0.821 & 0.040 & 0.000 & -0.900 to & -0.743 \\
\hline Constant & -13.85 & 0.068 & 0.000 & -13.987 to & -13.717 \\
\hline
\end{tabular}

Table 3 Poisson model for Canada

\begin{tabular}{|c|c|c|c|c|c|c|}
\hline Variable & Coefficient & $\begin{array}{l}\text { Standard } \\
\text { error }\end{array}$ & $p$ Value & $95 \%$ conf & iden & ce interval \\
\hline \multicolumn{7}{|l|}{ Sex } \\
\hline Female & -0.297 & 0.055 & 0.000 & -0.404 & to & -0.189 \\
\hline \multicolumn{7}{|l|}{ Age } \\
\hline $45-49$ & 0.643 & 0.201 & 0.001 & 0.248 & to & 1.038 \\
\hline $50-54$ & 1.197 & 0.188 & 0.000 & 0.829 & to & 1.564 \\
\hline $55-59$ & 1.572 & 0.182 & 0.000 & 1.216 & to & 1.928 \\
\hline $60-64$ & 1.981 & 0.177 & 0.000 & 1.634 & to & 2.329 \\
\hline $65-69$ & 2.339 & 0.175 & 0.000 & 1.996 & to & 2.682 \\
\hline $70-74$ & 2.575 & 0.175 & 0.000 & 2.232 & to & 2.919 \\
\hline $75-79$ & 2.942 & 0.175 & 0.000 & 2.598 & to & 3.286 \\
\hline $80-84$ & 2.960 & 0.185 & 0.000 & 2.597 & to & 3.323 \\
\hline $85+$ & 3.353 & 0.186 & 0.000 & 2.989 & to & 3.718 \\
\hline \multicolumn{7}{|l|}{ Time period } \\
\hline $1960-64$ & -0.150 & 0.110 & 0.174 & -0.366 & to & 0.066 \\
\hline $1965-69$ & -0.207 & 0.109 & 0.056 & -0.420 & to & 0.006 \\
\hline $1970-74$ & -0.115 & 0.103 & 0.267 & -0.317 & to & 0.088 \\
\hline $1975-79$ & -0.233 & 0.103 & 0.024 & -0.436 & to & -0.031 \\
\hline $1980-84$ & -0.508 & 0.107 & 0.000 & -0.717 & to & -0.298 \\
\hline $1985-89$ & -0.424 & 0.102 & 0.000 & -0.624 & to & -0.224 \\
\hline Constant & -13.59 & 0.176 & 0.000 & -13.940 & to & -13.248 \\
\hline
\end{tabular}

Useful information can be obtained from epidemiological studies, as observed age variations can be used to estimate the number of rate limiting steps involved. Cancer of the eye is a frequently used proxy measure for uveal melanoma, ${ }^{120-22}$ which we have used to examine the change in age specific mortality rates for cancer of the eye for England and Wales, USA, and Canada. The most commonly observed age pattern in cancer rates is a log-log relation $\left(\right.$ rate $=\operatorname{age}^{\mathrm{N}}$ ), such as that found in skin, gastrointestinal, and urinary tract cancers. ${ }^{23}$ It is also the pattern observed in skin painting experiments in mice and it has been interpreted as reflecting life long exposure to small amounts of a carcinogen starting at, or within, a decade of birth. ${ }^{23}$ This pattern is consistent with the results of our previous work implicating environmental factors in the aetiology of uveal melanoma (based upon observation of a marked decline in age standardised incidence and mortality over time for the $\mathrm{USA}^{22}$ ). An advantage of the log-log model is that the exponent, $\mathrm{N}$, provides an estimate of the number of rate limiting steps occurring. The value of $\mathrm{N}$ lies between 3 and 6 for most cancers. By using incidence and mortality, the difference between these estimates can be used to determine the number of rate limiting steps required for a tumour to progress from primary to metastatic disease. This can be compared with results from our previous studies on prognostic factors for the development of metastatic disease. ${ }^{2425}$

\section{Materials and methods \\ EPIDEMIOLOGY}

Melanoma of the eye is not represented as a unique entity in the International Classification of Disease (ICD). It has, however, become standard practice ${ }^{120-22}$ to treat eye cancers in adults as a surrogate measure, as $90 \%$ are ocular melanomas ${ }^{1}$ and the large majority of these involve the uveal tract. ${ }^{2}$

Data on the number of deaths from cancer of eye and population estimates during the period 1955-89 in 5 year age bands and 5 year calendar periods for the USA, Canada, and England and Wales, were provided by the International Agency for Research on Cancer. Data on incidence rates for England and Wales for the years 1971-88 were extracted from tables of cancer notifications for the age range 30-65 years, provided by the Office for Populations Census and Surveys.

The data for each country were modelled using the Poisson regression technique. ${ }^{26}{ }^{27}$ For each Poisson regression model, the dependent variable was the count, the population at risk was the offset, and the predictor variables were time period, age period, and sex. Each of the predictor variables was classified as a categorical variable, with the first category being the reference category (male for sex, 1955-9 for time period, and ages 40-44 for age period). Analysis was performed using STATA ver 3.1.

HISTOPATHOLOGY

This study has been fully reported elsewhere. ${ }^{242528}$ In brief, the sample of 123 cases represented all patients treated by enucleation at Moorfields Eye Hospital from 1979 to 1986 and those treated between 1987 and 1989, who were known to have died from metastatic uveal melanoma. The information recorded was largest tumour diameter $(\mathrm{mm})$, the cell type (according to the Callender classification), the PAS pattern, ${ }^{25}$ the mitotic count (the number per 20 high power fields with $\times 40$ objective), the lymphocytic infiltrate and the 


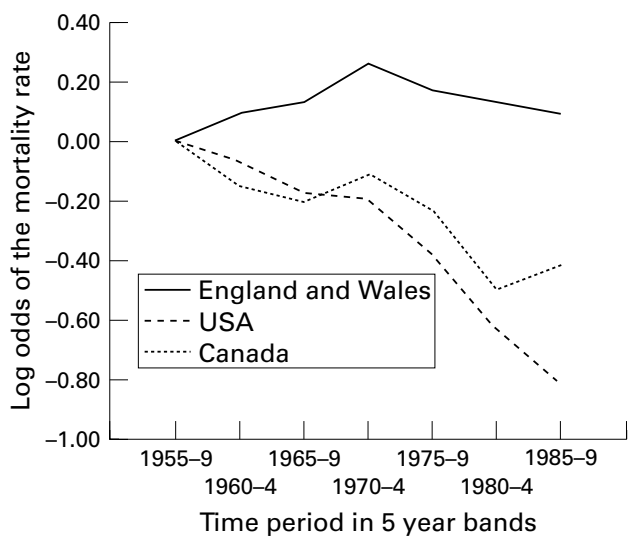

Figure 1 Log odds for the mortality for cancer of the eye in 5 year bands for England and Wales, USA, and Canada for the years 1955-89.

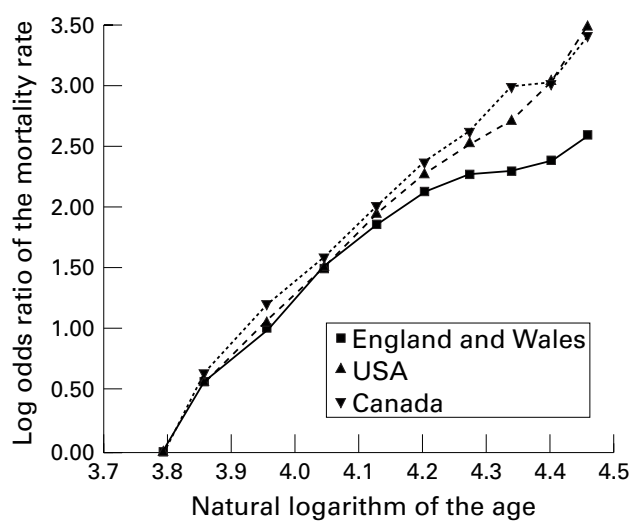

Figure 2 Log odds for the mortality for cancer of the eye in 5 year age bands for England and Wales, USA, and Canada for the years 1955-89.

microvessel density (section bleached and stained with factor VIII related antigen to demonstrate the blood vessels the density was determined by counting the number of vessels in $0.25 \mathrm{~mm}^{2}$ in area of maximum vessel density and the score underwent the square transformation before further analysis ${ }^{24}$ ). The data were analysed by entering them into a Cox's proportional hazard model in a stepwise manner, on the basis of their likelihood ratios (probability for entry into the model was 0.05 or less and probability for removal of 0.1 or more).

Table 4 Observed and expected mortality by age based on the log-log model

\begin{tabular}{lcc}
\hline Age (years) & $\begin{array}{l}\text { Observed } \\
\text { mortality rates } \\
\text { (per million) }\end{array}$ & $\begin{array}{l}\text { Predicted } \\
\text { mortality rates } \\
\text { (per million) }\end{array}$ \\
\hline $30-34$ & 0.45 & 0.41 \\
$35-39$ & 0.72 & 0.77 \\
$40-44$ & 1.27 & 1.36 \\
$45-49$ & 2.22 & 2.24 \\
$50-54$ & 3.43 & 3.52 \\
$55-59$ & 5.55 & 5.31 \\
$60-64$ & 7.94 & 7.73 \\
$65-69$ & 10.24 & 10.94 \\
$70-74$ & 11.59 & 15.09 \\
$75-79$ & 11.66 & 20.38 \\
$80-84$ & 12.85 & 27.02 \\
$>85$ & 15.69 & 35.22 \\
Standardised mortality rate* & 3.78 & 4.48 \\
\hline
\end{tabular}

${ }^{\star}$ Standard rates for ages of 30 years and older based on world standard population. ${ }^{48}$

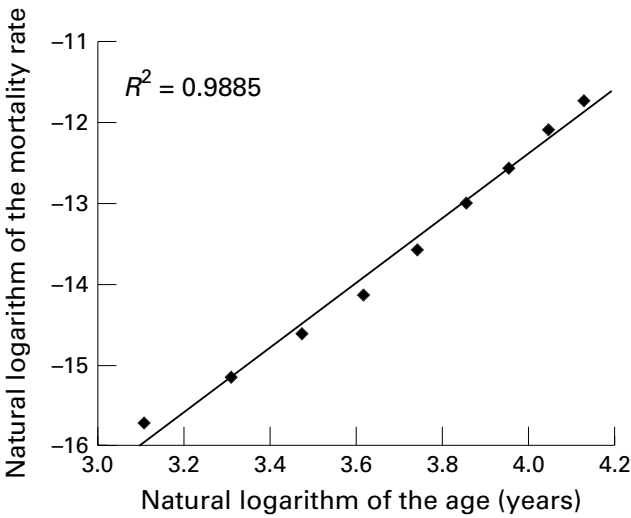

Figure 3 Log-log plot of the mortality by age for England and Wales averaged for the period 1950-89 for the age range 20-65 years.

\section{Results}

MORTALITY TRENDS OVER TIME

We have previously reported that the mortality in the USA is declining, in contrast with England and Wales. ${ }^{22}$ Poisson regression was performed for the age groups 40 and upwards and the results are presented in Tables $1-3$. For each Poisson regression model, the dependent variable was the count, population was the offset, and the predictor variables were time, age, and sex. Again, each of the predictor variables was classified as a categorical variable, with the first category being the reference category (male for sex, 195-59 for time period, and ages 40-44 for age period). In all three countries, the rates for women were significantly lower than those for men. The Poisson regression confirmed our previously reported finding that mortality is declining in the USA ${ }^{22}$ and demonstrated a similar downward trend for Canada as well (see Fig 1).

INCIDENCE AND MORTALITY TRENDS BY AGE

The model that was fitted to the data was a log-log model. This model assumes that the relation between rate and age is:

rate $=\operatorname{age}^{\mathrm{N}}$

The log of the odds ratio (the odds ratio for rare diseases approximates the relative risk) against the natural logarithm of the age is plotted in Figure 2. This provided a reasonable straight line relation for the data from the USA

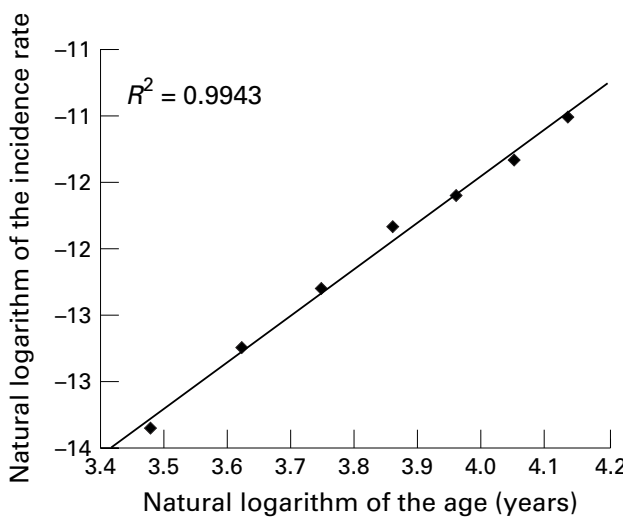

Figure 4 Log-log plot of the incidence data for England and Wales averaged for the years 1971-88 for the age range 30-65 years. 
Table 5 Final Cox regression model for survival in the study reported in Foss et al ${ }^{24}$

\begin{tabular}{llllll}
\hline Variable & $\beta$ & Exp $\beta$ & $\begin{array}{l}\text { 95\% confidence } \\
\text { interval for exp } \beta\end{array}$ & Wald & Significance \\
\hline $\begin{array}{l}\text { Transformed }{ }^{\star} \text { microvessel count } \\
\text { Tumour size (LTD) }\end{array}$ & 0.366 & 1.44 & $1.23-1.70$ & 19.5 & $<0.00005$ \\
\hline
\end{tabular}

${ }^{\star}$ The count underwent a square root transformation. Most count data can be made to follow a normal distribution by this technique.

and Canada, but there was significant deviation from a straight line relation for the data from England and Wales.

There are two explanations for the observed deviation in rates from the log-log model. One is underreporting and the other is increasing underdiagnosis in the older age groups. In order to estimate this degree of underdiagnosis/underreporting, we first calculated the linear regression coefficients for the logarithm of the mortality regressed on the natural logarithm of the age for the range 30-59 years. The final equation was as follows: $\log$ of the rate (per million population) = $-30.406+(4.5067 \times$ natural logarithm of the age (years)). The regression line was then extrapolated for the age range of 60 years and over. Table 4 shows the observed mortality and the expected mortality on the basis of the log linear model. These results suggest a marked overall underreporting or underdiagnosis, estimated at $16 \%$ for a standard population aged 30 years and over, increasing to $30 \%$ among those aged 60 and over.

As stated earlier, an advantage of the log-log model is that the exponent, $\mathrm{N}$, provides an estimate of the number of rate limiting steps occurring, with the value of $\mathrm{N}$ falling between 3 and 6 for most cancers. Figures 3 and 4 show the log-log plots for incidence and mortality for England and Wales. The slope of the gradient is 3.50 for the incidence (using data for England and Wales for the age range 30-65 years for the years 1971-88) and 3.98 for the mortality (using data for the years 1950-89 for the age range 20-65 years for England and Wales).

These results provide further evidence that three to four rate limiting steps or events are required to develop ocular cancer and that four rate limiting steps are required to die from the

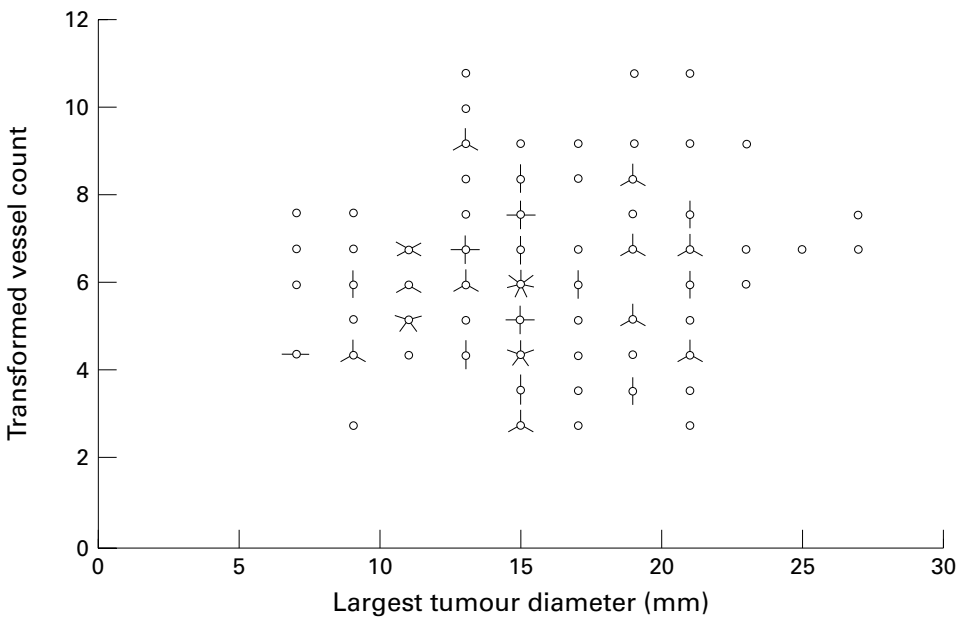

Figure 5 Scatter plot, using sunflowers, of microvessel density against largest tumour diameter showing the two measures to be independent. disease. This suggests that there is, at most, only a single rate limiting step between developing an ocular melanoma and dying from it.

MODELLING THE DEVELOPMENT OF METASTATIC DISEASE

Further analysis of our previous study provided a similar estimate for the number of rate limiting steps between developing primary and disseminated disease. ${ }^{24} 25$ In that study, angiogenesis was the single most important prognostic factor and one of only two factors, the other being tumour size, that entered into the final model (see Table 5). As the scatter plot shows (Fig 5), and the multivariate analysis confirms, the two factors of size and angiogenesis were completely independent. We therefore combined these two factors, which were weighted according to their beta coefficients in the Cox regression model and then summed to generate a composite score (summary score = $1 / 2$ (vessel count) + largest tumour diameter in $\mathrm{mm})$. On the basis of this summary statistic, we divided the 123 cases into three equal sized groups (or tertiles). Kaplan-Meier curves for each group are plotted in Figure 6.

The resulting plots gave lines that could be readily modelled by the equation:

$$
\mathrm{N} / \mathrm{No}=\mathrm{e}^{-\mathrm{kt}}
$$

where $\mathrm{N}$ is the number of cases, No is the initial number of cases, (therefore $\mathrm{N} / \mathrm{No}$ is the proportion of surviving cases), $\mathrm{t}$ is time, and $\mathrm{k}$ is a constant which, by analogy with radioactive decay equations could be called the decay constant. This is the equation of first order kinetics, arguing that there is only one unexplained process occurring and that the difference between good and poor prognostic cases is simply the value of the decay constant. The $\mathrm{k}$ value for the good prognosis curves was $0.0020 /$ month, $0.0066 /$ month for the middle prognosis curve, and $0.0181 /$ month for the poor prognostic group. The relation between median survival and the decay constant is the relation:

Median survival $=\ln 2 / \mathrm{k}=0.6931 / \mathrm{k}$

The median survival of the poor prognosis group was 38 months and 105 months for the middle prognostic group. If one extrapolates for the good prognosis group (one must always interpret any value obtained by extrapolation beyond the period of observation with caution), then the figure is 342 months or 28.5 years.

These model curves are presented in Figure 6 , demonstrating a good fit to the observed data.

\section{Discussion}

The epidemiological data we have presented are of cancer of the eye, as it has become standard practice to treat this as a surrogate measure of ocular melanoma. The decline in incidence and mortality over time for this diagnosis is fully discussed elsewhere. ${ }^{22}$ Empirically, ocular melanoma rates versus age followed the most commonly observed pattern for cancers and the log-log model gave a good 
fit for the America and Canadian data. The model also fitted the data for England and Wales up to the age of 65 , though not for older age groups.

The most likely explanation for the lower rates observed in England and Wales is underdiagnosis, but underreporting cannot be excluded. There is increased incidence of mimicking lesions in the elderly, particularly retinal detachments, haemorrhages, choroidal detachments, disciform macular degeneration, and others, ${ }^{29}$ which may account for this. Other evidence favouring underdiagnosis is the well known exponential increase in the category "death from unspecified cause" and death from "cancer of unknown primary" in the older age groups in cancer registration data. The estimated underdiagnosis rate in those over the age of 65 years was $30 \%$. We have previously reported the decline in incidence and mortality for the USA and have extended that observation to Canada in this paper. By contrast, rates for England and Wales have remained relatively constant. ${ }^{22}{ }^{30}$ This stabilisation, combined with evidence of an increasing rate of underdiagnosis with age in England and Wales, is disturbing. There has been concern in the past regarding overdiagnosis resulting in inappropriate enucleations running at $10 \%$ at non-specialist, compared with $5 \%$ at specialist institutions, ${ }^{31}$ but these figures are now dated and the most recent report gives an error rate of under $0.5 \% .^{32}$ It would seem that underdiagnosis may now be a greater problem than overdiagnosis. Recently, three national centres (in Liverpool, London, and Sheffield) have been established for the treatment of ocular cancer. It is to be hoped that the establishment of these centres and increased recognition of the problem of underdiagnosis may result in improved recognition and management of this condition.

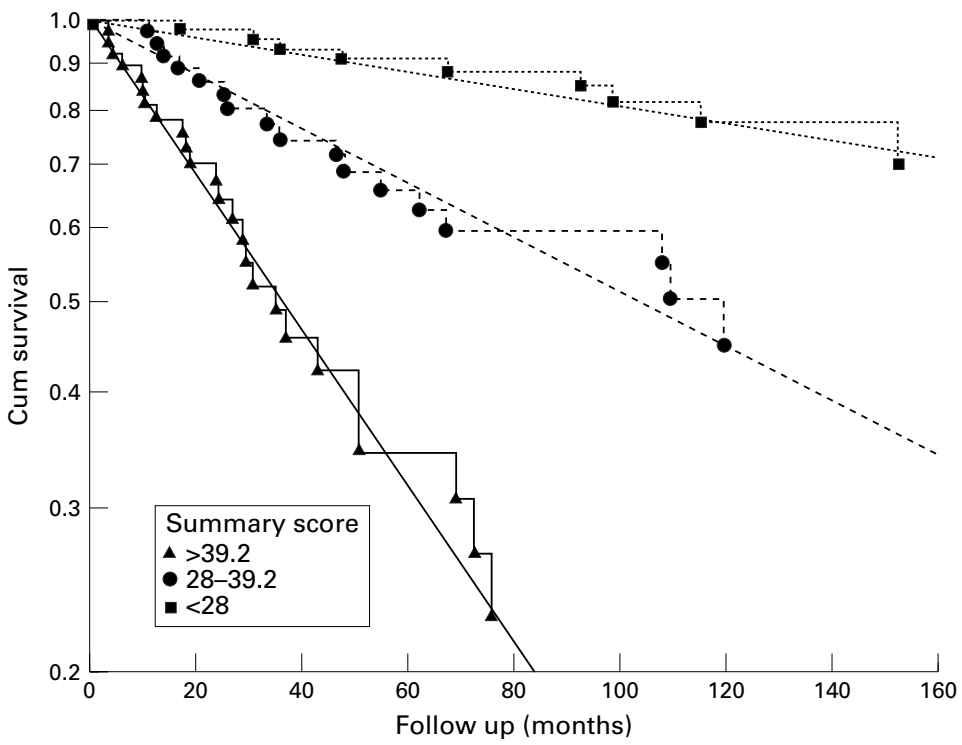

Figure 6 Kaplan-Meier curves on the basis of the summary statistic (half the microvessel count per $0.25 \mathrm{~mm}^{2}$ plus the largest tumour diameter in $\mathrm{mm}$ ) dividing 123 patients into three equal sized groups. The full study is reported in Foss et al. ${ }^{24}$ The fitted lines follow the equation of $N / N o=e^{-k t}$ with $t$ being time measured in months, N/No being the proportion of surviving patients, and $k$ being the "decay constant" with value of $0.0020 /$ month for the good prognosis group, $0.0066 /$ month for the intermediate group, and $0.0181 /$ month for the poor prognosis group.
It should be noted that the problem is most marked in the elderly, raising questions regarding the accessibility of these centralised services to the elderly and infirm.

In passing, it is well known that patients presenting with larger tumours tend to be older ${ }^{33}$ and this has been taken as evidence that uveal melanoma is very slow growing. An alternative explanation, supported by these data, is that diagnosis is delayed in older patients.

The motivation for fitting the log-log model is that this is the most commonly observed pattern for cancers, including skin, gastrointestinal, and urinary tract cancers. ${ }^{23}$ As noted earlier, it is also the pattern observed in skin painting experiments in mice and it has been interpreted as reflecting lifelong exposure to small amounts of a carcinogen starting at, or within, a decade of birth. ${ }^{23}$ The log-log model is also consistent with our observation of declining eye cancer rates in the USA, which argue for an environmental aetiology. ${ }^{22}$ The value of $\mathrm{N}$ lies between 3 and 6 for most cancers and this has been interpreted as the number of rate limiting processes required for a cancer to develop. This model, therefore, allows one to calculate the number of independent processes occurring. Clearly, one would expect that fewer steps would be required to develop a primary tumour than to develop a secondary tumour and the difference between the two can give an indication of the number of rate limiting steps necessary to develop metastases from a primary tumour. The figures obtained for uveal melanoma were 3.5 and 4.0 respectively. This suggests that approximately three rate limiting steps are required to develop a primary tumour, whereas only one additional rate limiting step is required for a primary tumour to proceed to metastatic disease.

The quality of the epidemiological data is dependent on correct diagnoses and on accurate and comprehensive reporting and it is not possible to directly assess these factors. Accordingly, one must express caution about any conclusion based purely on the registration data. However, analyses of our pathological data gives rise to very similar results which greatly increases our confidence in the modelling process. The pathology data demonstrate that tumour growth and angiogenesis are independent (see Fig 5) and therefore belong to different processes; these would account for at least two of the three rate limiting steps. In fact one of the processes may account for two rate limiting steps, as once these two processes are taken into account, mortality follows first order kinetics which argues for only one rate limiting step unaccounted for (see below).

Evidence is now amassing that angiogenesis is a key process in many tumour types. The idea that a blood supply is necessary for tumour growth is, in itself, unsurprising. ${ }^{34}$ Of greater interest is the concept that angiogenesis is a prerequisite for metastatic spread and that the degree of angiogenesis present is a major prognostic factor. This was first shown to be the case by Weidner et $a l^{35}$ in breast cancer, who identified hot spots of microvessel density, 
measured by counting the number of blood vessels in an area selected for the highest blood vessel count (termed the microvessel density). The measure showed powerful predictive value and, subsequently, this observation has been replicated both in breast and many other cancer types (see Craft and Harris for review $\left.^{36}\right)$. We applied the same methodology to a sample of 123 uveal melanomas and obtained similar results. ${ }^{24}{ }^{25}$ Angiogenesis was identified as the single most important prognostic factor and one of only two factors that entered into the final model, the other being tumour size (see Table 1). As tumour size and angiogenesis were independent prognostic factors, they were combined (weighted according to their Cox regression coefficients) to generate a summary statistic. On the basis of this summary statistic, we divided the 123 cases into three groups; their Kaplan-Meier curves are plotted in Figure 6.

The surprising observation is that the Kaplan-Meier curves follow first order kinetics (see Fig 6). Although extrapolation beyond the observation period must be made with great caution, the difference between the good, middle, and poor prognostic groups is simply the "half life" for this process: 28.5 years, 8.8 years, and 3.2 years, respectively. This finding has a number of implications. Principally, it suggests that there is only one rate limiting step required to develop metastases from the primary tumour, thus supporting conclusions drawn from analyses of the incidence and mortality data.

First order kinetics can be characterised by just one constant, which we have termed the decay constant. It should be noted that the difference between the good and poor prognostic group is determined by the value of the decay constant. These data were generated from enucleation specimens, so the primary tumour had already been removed and thus the process that is being modelled must have been occurring in already disseminated cells. Observed differences in the values of the decay constants must then reflect either the number, or the nature, of these disseminated cells (or a combination of the two). This model could easily be modified to explain long term cures. For example, one could readily hypothesise that the median survival of micrometastatic deposits is only 10 years and that failure for these cells to progress in this period of time results in their loss of viability and results in long term survival.

This model shares features in common with the Manschot-Van Peperzeel hypothesis, ${ }^{56}$ which states that seeding occurs early in the disease process. This model agrees that seeding can occur early. It disagrees with one of the key assumptions behind the Manschot-Van Peperzeel model which is the suggestion that metastatic deposits grow at the same rate of the primary. Recent work on animal models of metastatic disease suggests that in the initial stage, disseminated cells are far from dormant and show rapid turnover, but that cell division is balanced by apoptosis. ${ }^{37}{ }^{38}$ Such microdeposits are not vascularised and this would explain their small size and lack of progression. It is not surprising that such microdeposits cannot readily be detected and it provides an explanation for why screening tests for metastatic disease in uveal melanoma patients are usually negative at presentation, even in high risk cases. $^{39-42}$

The development of metastases depends upon the disseminated cells undergoing one final rate limiting step. It is the rate at which this step occurs that differentiates good from poor prognostic groups. Once this step has occurred, and overt metastatic disease has developed, the prognosis is then independent of the features of the primary tumour and is universally poor, with median survival of 6 months ${ }^{43}$ or less. ${ }^{44}$ The published experimental evidence referred to above suggests that this step may consist of the development of angiogenesis in the micrometastatic deposits. ${ }^{37} 38$ Cancer occurs as the result of somatic or acquired mutations; it is now thought that these "rate limiting events" are in fact mutations and it is likely that this "event" also involves a mutation. The long half life of the process for the good and intermediate prognostic groups would readily explain the occasionally long time gaps observed between treatment of the primary and the onset of metastatic disease ${ }^{45}$ without the need to invoke alternative mechanisms (such as immune modulation). Mutations are quantum events and this explains why a patient with a "good" prognostic tumour can die a decade before someone with a "poor" prognostic tumour. Quantum events, by their nature, can only be described in terms of probability functions and thus is seems that our understanding of the processes involved is surprisingly complete.

A consequence of this model is that the prognosis worsens with time as the primary tumour enlarges and becomes vascularised. It would therefore argue that prompt treatment, following diagnosis, would prevent deterioration in the prognosis (reflected by an increase in the value of the decay constant), but equally explains why this does not invariably result in a cure. A second implication is that tumour size and angiogenesis potentially incorporate all the prognostic information available in the primary tumour. The next stage is to try and understand what these events involve at a molecular level. One such event has probably already been identified as chromosome 3 monosomy. Loss of one copy of chromosome 3 is found in many cancers including uveal melanoma, where it has been shown to be of major prognostic significance. ${ }^{46} 47$ The challenge now is to explain the others.

We conclude that there is evidence for significant underreporting or underdiagnosis of ocular melanoma in England and Wales in people age over 65 years. In people under 65 years of age, one can generate a model of the disease which depends upon three rate limiting steps to generate a primary tumour and a fourth rate limiting steps to develop metastatic disease. The first three steps result in angiogenesis and growth of the tumour. The final rate limiting step from incidence to metastasis 
occurs in an already disseminated cell. The constructed model predicts that prompt treatment of the primary tumour does benefit survival.

1 Hakulinen T, Teppo L, Saxen E. Cancer of the eye, a review of trends and differentials. World Health Stat $Q$ 1978;31:143-58

2 Scotto J, Fraumeni JF Jr, Lee JAH. Melanomas of the eye and other noncutaneous sites: epidemiologic aspects. $\mathcal{f} \mathrm{Nat}$ Cancer Inst 1976;56:489-91.

3 Diener-West M, Hawkins BS, Markowitz JA, et al. A review of mortality from choroidal melanoma. II. A meta-analysis of 5-year mortality rates following enucleation, 1966 through 1988. Arch Ophthalmol 1992;110:245-50.

4 Zimmerman LE, McLean IW, Foster WD. Does enucleation of the eye containing a malignant melanoma prevent or accelerate the dissemination of tumour cells? $\mathrm{Br} \mathcal{F}$ Ophthatmol 1978;62:420-5.

5 Manschot WA, van Peperzeel HA. Choroidal melanoma. Enucleation or observation? A new approach. Arch Ophthalmol 1980;98:71-7.

6 Manschot WA, van Strik R. Uveal melanoma: therapeutic consequences of doubling times and irradiation results: a consequences of doubling times and
review. Int Ophthalmol 1992;16:91-9.

review. Int Ophthalmol 1992;16:91-9.
7 McLean IW, Foster WD, Zimmerman LE. Uveal melanoma: location, size, cell type, and enucleation as risk factors in metastasis. Hum Pathol 1982;13:123-32.

8 Zimmerman LE, McLean IW, Foster WD. Statistical analysis of follow-up data concerning uveal melanomas, and the influence of enucleation. Ophthalmology 1980;87:557-64.

9 Joynes F, Rous P. On the cause of localisation of secondary tumour at points of injury. $\mathcal{F} \operatorname{Exp}$ Med 1914;20:404-12.

10 Seigel D, Myers M, Ferris F, et al. Survival rates after enucleation of eyes with malignant melanoma. $\mathrm{Am} \mathcal{F} \mathrm{Oph}$ thalmol 1979;87:761-5.

11 Specht CS, McLean IW, Biscoe BW. Traumatic enucleation for posterior uveal melanoma. Am f Ophthalmol 1990;110: 518-21.

12 Char DH, Phillips TL. Pre-enucleation irradiation of uveal melanoma. Br f Ophthalmol 1985;69:177-9.

13 Bornfeld N, Huser U, Sauerwein W, et al. Preoperative irradiation before enucleation in malignant melanoma of the
uvea. Review of the literature and initial personal uvea. Review of the literature and initial personal
experiences. Klin Monatsbl Augenheilkd 1989;194:252-60.

14 Augsburger JJ, Lauritzen K, Gamel JW, et al. Matched group study of pre-enucleation radiotherapy versus enucleation alone for primary malignant melanoma of the choroid and ciliary body. Am F Clin Oncol 1990;13:382-7.

15 Luyten GPM, Mooy CM, Eijkenboom CMH, et al. No demonstrated effect of pre-enucleation irradiation on survival of patients with uveal melanoma. Arch Ophthalmo 1995;119:786-91.

16 Foss AJE, Guille MJ, Occleston NL, et al. The detection of melanoma cells in peripheral blood by RT-PCR. $\mathrm{Br} 7 \mathrm{Can}-$ cer 1995;72:155-9.

17 Charbit A, Malaise EP, Tubiana M. Relation between the pathological nature and the growth rate of human tumors. Eur f Cancer 1971;7:307-15.

18 Raivio I. Uveal melanoma in Finland: an epidemiological, clinical, histological and prognostic study. Acta Ophthalmo Copenh 1977; suppl 133:1-64.

19 Sobanski J, Zeydler L, Goetz J. Uber die therapie des intraokularen meanoma malignum. Klin Monatsbl Augenheilkd 1965;146:70-6.

20 Strickland D, Lee JAH. Melanomas of eye: stability of rates. Am F Epidemiol 1981;113:700-2.

21 Swerdlow AJ. Epidemiology of eye cancer in adults in England and Wales, 1962-1977. Am f Epidemiol 1983;118: $294-300$

22 Foss AJE, Dolin PJ. Trends in eye cancer mortality among adults in the USA and England and Wales. Br f Cancer 1996;74:1687-9.

23 Peto R. Cancer epidemiology and multistage models. In: Hiatt $\mathrm{HH}$, Watson JD, Winsten JA, eds. Origins of human cancer. New York: Cold Spring Harbor Publications, 1998.
24 Foss AJE, Alexander RA, Jefferies LW, et al. Microvessel count predicts survival in uveal melanoma. Cancer Res 1996;56:2900-3.

25 Foss AJE, Alexander RA, Hungerford JL, et al. Reassessment of the PAS patterns in uveal melanoma. $\mathrm{Br} \mathcal{F}$ Ophthalmol 1997;81:1691-2.

26 Armitage P and Berry G. Statistical methods in medical research. 2nd ed. Oxford: Blackwell Scientific Publications, 1987.

27 Stata Corporation. Stata reference manual: Release 3.1. 6th ed. TX: College Station, 1993.

28 Chana JS, Wilson GD, Cree IA, et al. c-myc, p53, and bcl-2 expression and clinical outcome in uveal melanoma. $\mathrm{Br} \mathcal{F}$ Ophthalmol 1999;83:110-14.

29 Grossniklaus HE, Green WR. Uveal tumors. In: Garner A, Klintworth GK, eds. Pathobiology of ocular disease. A dynamic approach. 2nd ed. New York: Marcel Dekker, 1994:1423-77.

30 Dolin PJ, Foss AJE, Hungerford JL. Uveal melanoma: is solar ultraviolet radiation a risk factor? Ophthalmic Epidemiol 1994;1:27-30.

31 Blodi FC, Roy PE. The misdiagnosed choroidal melanoma. Can f Ophthalmol 1967;2:209-11.

32 Collaborative Ocular Melanoma Study Group. Accuracy of diagnosis of choroidal melanomas in the Collaborative Ocular Melanoma Study Group. COMS Report number 1. Arch Ophthalmol 1990;108:1268-73.

33 McLean IW, Foster WD, Zimmerman LE, et al. Inferred natural history of uveal melanomas. Invest Ophthalmol Vis Sci 1980;19:760-70.

34 Folkman J, Klagsbrun M. Angiogenic factors. Science 1987; 235:442-7.

35 Weidner N, Semple JP, Welch WR, et al. Tumor angiogenesis and metastasis - correlation in invasive breast carcinoma. N Engl F Med 1991;324:1-8.

36 Craft PS, Harris AL. Clinical prognostic significance of tumour angiogenesis. Ann Oncol 1994;5:305-11.

37 O'Reilly MS, Holmgren L, Shing Y, et al. Angiostatin: a novel inhibitor that mediates the suppression of metastases by a Lewis lung carcinoma. Cell 1994;79:315-28.

38 Holmgren L, O'Reilly MS, Folkman J. Dormancy of micrometastases: balanced proliferation and apoptosis in the presence of angiogenesis suppression. Nat Med 1995;1: 149-53.

39 Zimmerman LE, McLean IW. Metastatic disease from untreated uveal melanomas. Am f Ophthalmol 1979;88: $524-34$

40 Pach JM, Robertson DM. Metastasis from untreated uveal melanomas. Arch Ophthalmol 1986;104:1624-5.

41 Wagoner MD, Albert DM. The incidence of metastases from untreated ciliary body and choroidal melanoma. Arch Ophthalmol 1982;100:939-40.

42 Hicks C, Foss AJE, Hungerford JL. Predicitive power of screening tests for metastasis in uveal melanoma. Eye 1998;12:945-8.

43 Jensen OA. Malignant melanomas of the uvea in Denmark 1943-1952. Acta Ophthalmol Copenh 1963;75(Supp1): $146-7$.

44 Seddon JM, Albert DM, Lavin PT, et al. A prognostic factor study of disease-free interval and survival following enucleation for uveal melanoma. Arch Ophthalmol 1983; 101:1894-9.

45 Shields JA, Augsburger JJ, Donoso LA, et al. Hepatic metastasis and orbital recurrence of uveal melanoma after 42 years. Am 7 Ophthalmol 1985;100:666-8.

46 Prescher G, Bornfeld N, Hirche H, et al. Prognostic implications of monosomy 3 in uveal melanoma. Lancet 1996;347: $1222-5$.

47 Sisley K, Rennie IG, Parsons A, et al. Abnormalities of chromosomes 3 and 8 in posterior uveal melanoma correlate with prognosis. Genes Chromosom Cancer 1997;19:22-

48 International Union against Cancer. Cancer incidence in five continents. Volume II. Geneva: IUAC, 1970. 